\title{
Artificial Neural Network Based Direct Torque Control for Variable Speed Wind Turbine Driven Induction Generator
}

\author{
D.V.Naga Ananth
}

\begin{abstract}
This paper presents an artificial neural network (ANN) based direct torque control (DTC) scheme to control speed and torque of IG drive over a wide speed range without using PWM controller. With the induction machine stator and rotor flux parameters, speed of IG is predicted by using ANNSP scheme. In wind turbine driven IG set, if wind speed alters, output torque of IG varies, results in variation of output voltage and electric power. In other circumstances, there may be requirement to change the IG speed, which has to be achieved more rapidly. Robust technique to reach the desired states in a stable manner is necessary for such a system. Hence this paper aims to present a technique to control speed and torque with very diminutive time delay compared to preceding techniques. Simulation results shows that the proposed prediction method effectively diminishes the torque and flux ripples under variable speed circumstances. The system is studied using MATLAB/SIMULINK, shows that ANN speed recognition optimization algorithm has better tracking capability and fitness, as well as favorable static and dynamic properties. The outputs of ANN mechanism is compared with that of PI controller and the results demonstrate the influence of ANN is enhanced and fast compared to PI. The system is also verified and proved to be operated stably with very low speed, sudden speed reversals, at low torque and at high torque.
\end{abstract}

Index Terms-DTC, PI, ANN, wind turbine, variable speed induction generator, torque and flux ripples, PWM.

\section{INTRODUCTION}

Direct Torque Control describes the way to control torque and speed, directly based on the electromagnetic state of the machine. DTC can be pertinent to asynchronous machines, permanent magnet machines etc. For a DC machine, field or armature currents are controlled to adjust the speed or torque, but to adjust these parameters for an induction machine, either input frequency and/ or voltage have to be controlled by using PWM, SPWM or SVPWM techniques $[6,12$, and 13]. DTC is the first technology to control the "real" motor variables of torque and flux [9]. Because torque and flux are motor parameters that are being directly controlled, there is no need for a modulator, as used in PWM drives, to control the frequency and voltage. This, in effect, cuts out the middle man and dramatically speeds up the response of the drive to the changes in required torque. DTC also provides precise torque control without the need for a feedback device.

The stability of the machine can me maintained even at

D. V. Naga Ananth is with VITAM Engineering College, Vishakapatnam, India (nagaananth@gmail.com). full, zero or reverse speed is good and both torque and speed accuracy can be maintained at very low speeds at light loads $[10,22]$. By using multilevel inverters [33], the resolution of the voltage vectors can be improved and hence, more smooth torque and flux responses. Nevertheless, due to the increased number of power switches, the system cost and complexity increase. Switching losses inevitably increase too and the overall system efficiency decreases. A modified DTC scheme that utilizes space vector modulation (SVM) was reported in [34]. Stability problems occur especially in the field weakening range, where a large load angle is necessary to produce a high torque in such systems.

The benefit of DTC technology includes exceptional dynamic performance features, many of which are obtained without the need for an encoder or tachometer to monitor shaft position or speed $[11,12]$ :

When compared to the classical DTC scheme, the proposed technique can suppress torque and flux ripples significantly. Furthermore, with the adoption of the ANNSP technique, a constant switching frequency is obtained. At the same time, all the advantages of the DTC are not endangered. Even the low speed performance is still an issue to be resolved. A low speed operation, which is substandard till now, this technique proves the capability to withstand at low or zero speed, speed reversal at low or high speed operation.

The organization of this paper depart as, Section 2 will present the concept of DTC for induction machine using the proposed scheme. Section 3 and 4 describes wind turbine modeling and mathematical representation using DTC-ANN technique. The simulation and experimental results will be presented in Sections 5 and 6 describe the design using simulink and results. In section 6 , three cases are studied, first with constant generator speed with different wind speeds, second with variation in both generator and wind speed and last but not the least, at constant wind speed and very low and reverse generator speed of operation. Sections $7,8,9$ and 10, presents the conclusions, related work in the same area, machine parameters used in proposed system and references aided to do this work.

The results of this method using ANN is discussed and compared with conventional DTC with PI controller.

\section{DTC CONTROL THEORY PROPOSED}

The machine can be made to run at any desired speed or can make to stop using this technique, without much delay or loosing stability. The DTC is mainly used in the objective to recover the reduction of the undulations or the flux's distortion, and to have superior dynamic performances. 


\section{A. DTC's with ANN Torque Control Loop.}

DTC-ANN depends only on stator current and rotor flux, which is used to estimate the speed of the drive. DTC parameters are less sensitive to be tuned and provide high dynamic response of torque and flux, than the classical vector control. The analytical relationship between the applied voltage vector and corresponding torque and flux variations can be derived as in [26].

In this paper, ANN technique is used, training and generalization is easy, possibility of approximating nonlinear functions, simple architecture, insensitivity to the distortion of the network, prediction of actual value to reference is accurate, error mitigation is random and sophisticated technique where parameters changing is more, self learning. The ANNs are capable of learning the desired mapping between the inputs and outputs signals of the system without knowing the exact mathematical model of the system [20, 22 and 25]. Since the ANNs do not use the mathematical model of the system, these are excellent estimators in non linear systems [6-8]. Various ANN based control strategies have been developed for direct torque control of wind driven induction generator set to overcome the scheme drawback [15-19].

The ANNs are capable to learn the desired mapping between the inputs and outputs signals of the system without perception of the exact mathematical sculpt of the system. [27] - [29]. Various ANN based control strategies have been developed for direct torque control induction motor drive to overcome the scheme drawback [30] - [32].

\section{B. Algorithm for Optimizing Ann Algorithm is Summarized as Follows:}

(1) Make use of multi or bit-optimizing algorithm to learn all data samples, so as to obtain the weight values and threshold values of the first function network.

(2) Filter all the samples. The filtering method is as follows:

a) Construct the BP network with the weight values and threshold values of the first function network;

b) Calculate the absolute value of difference which subtract the neural network outputs from the actual outputs ;

c) Select the samples who's the absolute value is bigger than the required accuracy as the new data sample of the second function network.

At the same time, revise the original samples as follows: Make the actual outputs of the data included in the new samples be 1; make the actual outputs of the data included in the remaining samples be 0 . Hereinafter such sample is named as "samples tagged by function network".

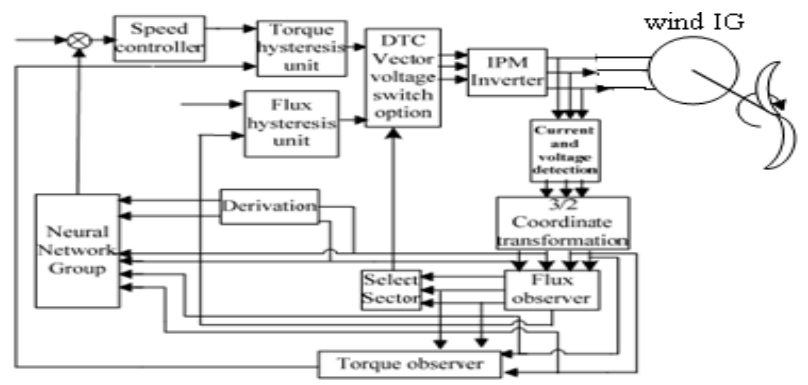

Fig. 2.1 Shows the block diagram representation of DTC based ANN for wind turbine driven induction generator set
Train the neural network with the isolated new samples and the samples tagged by function network respectively. The resulting weight values and the threshold values from the training of the isolated new samples will be used in the elaborate function network, and the resulting weight values and the threshold values from the training of the samples tagged by function network will be used in the input identifier.

\section{Theoretical Wind Turbine Model}

There are two types of wind turbines namely vertical axis and horizontal axis types. Horizontal axis wind turbines are preferred due to the advantages of ease in design and lesser cost particularly for higher power ratings [21].

The power captured by the wind turbine is obtained as

$$
\mathrm{P}=\frac{1}{2} \pi \rho \mathrm{R}^{3} \mathrm{~V}^{2} \mathrm{C}_{\mathrm{P}}
$$

where the power coefficient $\mathrm{Cp}$ is a nonlinear function of wind velocity and blade pitch angle and is highly dependent on the constructive features and characteristics of the turbine.

It is represented as a function of the tip speed ratio $\lambda$ given by

$$
\lambda=\frac{\mathrm{R} \omega_{\mathrm{t}}}{\mathrm{V}}
$$

It is important to note that the aerodynamic efficiency is at the optimum tip speed ratio. The torque value obtained by dividing the turbine power by turbine speed is formed obtained as follows:

$$
\mathrm{T}_{\mathrm{t}}\left(\mathrm{V}, \omega_{\mathrm{t}}\right)=\frac{1}{2} \pi \rho \mathrm{R}^{2} \mathrm{C}_{\mathrm{t}}(\lambda) \mathrm{V}^{3}
$$

where $\mathrm{Ct}(\lambda)$ is the torque co-efficient of the turbine, given by

$$
C_{t}(\lambda)=\frac{C_{p}(\lambda)}{\lambda}
$$

where the power co-efficient $\mathrm{Cp}$ is given by

$$
C_{p}(\lambda)=\left(\frac{116}{\lambda .1}-(0.4 \beta)-5\right) 05 \mathrm{e}^{\frac{-x / 2}{\lambda \lambda}}
$$

where

$$
\lambda_{1}=\frac{1}{\left(\frac{1}{(\lambda+0.089 \beta)}-\frac{0.035}{\beta^{3}+1}\right)}
$$

\section{MATHEMATICAL REPRESENTATION OF DTC-ANN WIND TURBINE SYSTEM}

The ANN is trained by a learning algorithm which 
performs the adaptation of weights of the network iteratively until the error between target vectors and the output of the ANN is less than an error goal. The most popular learning algorithm for multilayer networks is the back-propagation algorithm and its variants [19]. The latter is implemented by many ANN software packages such as the neural network toolbox from MATLAB.

The most popular learning algorithm for multilayer networks is the back-propagation algorithm and its variants [19]. The latter is implemented by many ANN software packages such as the neural network toolbox from MATLAB [19] [20].

Stator Flux and Torque Estimation: The components of the current $\left(\mathrm{I}_{\mathrm{s} \alpha}, \mathrm{I}_{\mathrm{s} \beta}\right)$, and stator voltage $\left(\mathrm{V}_{\mathrm{s} \alpha}, \mathrm{V}_{\mathrm{s} \beta}\right)$ are obtained by the application of the transformation given by (5) and (6), [1] :

$$
\begin{gathered}
\left\{\begin{array}{l}
I_{s \alpha}=\sqrt{\frac{2}{3}} I s a \\
I_{s \beta}=\frac{1}{\sqrt{2}}(I s b-I s c)
\end{array}\right. \\
\left\{\begin{array}{l}
V_{s \alpha}=\sqrt{\frac{2}{3}} U_{0}\left(C_{1}-\frac{1}{2}\left(C_{2}+C_{3}\right)\right) \\
V_{s \beta}=\frac{1}{\sqrt{2}} U_{0}\left(C_{2}-C_{3}\right)
\end{array}\right.
\end{gathered}
$$

The components of the stator flux $(\phi s \alpha, \phi s \beta)$ given by (7).

$$
\left\{\begin{array}{l}
\bar{\varphi}_{s \alpha}=\int_{0}^{\infty}\left(\bar{V}_{s \alpha}-R_{s} \bar{I}_{s \alpha}\right) d t \\
\bar{\varphi}_{s \beta}=\int_{0}^{\infty}\left(\bar{V}_{s \beta}-R_{s} \bar{I}_{s \beta}\right) d t
\end{array}\right.
$$

The stator flux linkage phase is given by (8).

$$
\varphi_{s}=\sqrt{\varphi_{s \alpha}^{2}+\varphi_{s \rho}^{2}}
$$

The electromagnetic couple be obtained starting from the estimated sizes of flux $\left(\phi_{s \alpha}, \phi_{s \beta}\right.$ and calculated sizes of the current, $I_{s \alpha} I_{s \beta}$ )

$$
\Gamma_{e m}=p\left(\varphi_{s \alpha} I_{s \beta}-\varphi_{s \beta} I_{s \alpha}\right)
$$

The stator resistance Rs can be assumed constant during a large number of converter switching periods $T_{e}$. The voltage vector applied to the induction motor remains also constant one period $\mathrm{T}_{\mathrm{e}}$. Therefore, resolving first equation of system leads to:

$$
\begin{gathered}
\bar{\varphi}_{s}=\int_{0}^{\tau}\left(\bar{V}_{s}-R_{s} \bar{I}_{s}\right) d t \\
\bar{\varphi}_{S}(t) \approx \bar{\varphi}_{S 0}+\bar{V}_{s} T_{e}
\end{gathered}
$$

In equation (11); $\varphi_{\mathrm{s} 0}$ stands for the initial stator flux condition. This equation shows that when the term RsIs can be neglected, (in high speed operating condition for example), the extremity of stator flux vector $\mathrm{V}_{\mathrm{s}}$. Furthermore, the instantaneous flux speed is only governed by voltage vector amplitude [1][4].

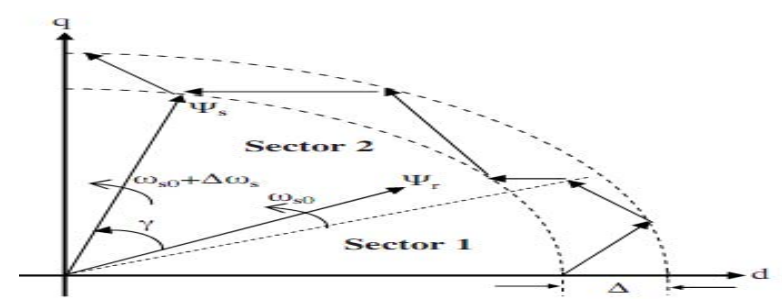

Fig. 4.1. Shows the phasor diagram representation of stator flux, Parks transformation components (d andq)

Fig 4.1shows the stator flux behavior as compared to the rotor flux after pulsating the stator with a step variation, Wso $=\mathrm{Wso}+\Delta \mathrm{Ws}$. where $\mathrm{Ws} 0$ is the initial pulsation and $\Delta \mathrm{Ws}$ is the step variation.

ANN based voltage vector estimator: Here we have used a feed forward neural network to select the voltage vector. The relation of variables used in the proposed scheme is as shown in Fig. 4.2..

First is to estimate the value of stator flux position, $\theta \mathrm{e}$ as shown in the Fig. 5. This is the angle between the stator flux and the rotor flux. The input layer has 6 neurons of hyperbolic tangent sigmoid transfer function, first hidden layer has 4 neurons of $\log$ sigmoid transfer function and the output layer has 1 neuron of linear function with weighing functions. Necessity steps to adjust these weights associated with the hidden neurons can be made through the training of the neurons. Levenberg- Marquardt back-propagation method is used here for training the network [18]. The inputs given are d-axis stator flux' and 'q-axis stator flux'.

Second neural network is used to determine the sector number for the estimated value of $\theta \mathrm{e}$. There are total of six sectors, each sector of 60 degree. Again three layers of neurons are used but with a 5-4-1 feed forward configuration as shown in Fig. 4.2. Input layer is of $\log$ sigmoid transfer function, hidden layer is of hyperbolic tangent sigmoid function and the output layer is of linear transfer function. The training method used was LevenbergMarquardt back-propagation. The input given is the angle theta since sector selection is purely based on theta.

Last neural network is for the selection of voltage vector as given in Fig. 4.2, which is based on two inputs, stator current, rotor flux. Network taken this time is a 3-5-1 feed forward network with first layer of log sigmoid transfer function, second layer of hyperbolic tangent sigmoid transfer function and third layer of linear transfer function. Training method used was again Levenberg-Marquardt back-propagation.

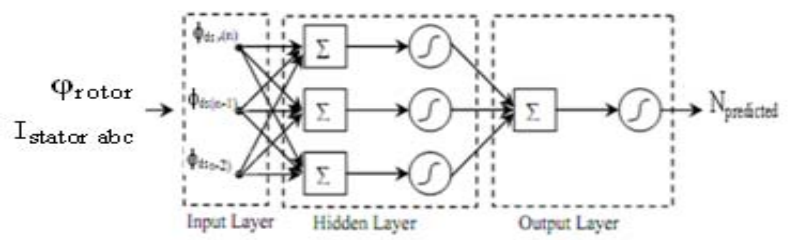

Fig. 4.2. Shows the speed to torque relation using ANN system for three layer system with weighing functions and relationship with arrow. 
The ANN based speed Predictor (ANNSP) structure is as shown in Fig. 4.2.

\section{Verification of The System Using Semolina}

The proposed system was implemented using MATLAB/Simulink software; the wind turbine system is taken from matlab library. The complete system is a closed loop system with speed output of the machine compared with the reference. The ANN feed forward self learning technique is used to estimate the speed of the machine using current and flux parameters. The ANN will have flux and current as inputs, with speed estimation as output.

The speed is controlled by using transfer function, which gives the desired torque for DTC calculation. The subsystem "DTC" mechanism is shown in the figure 5.1. The induction machine model was done referring to $[1,2,3,4,8]$.

This machine model can work as a generator and also as motor with changes in torque value from negative to positive. Negative torque implies, the machine works as generator and positive torque for motor. But in this paper, we have considered generator characteristics, driven by wind turbine.

\section{A. DTC Implementation:}

The DTC implementation was [5,6, 9,10], of which [9] gives very detailed overview of industrial requirement, present challenges researchers facing etc. So, definitely a good technique for robust control is necessary. Papers [1018] gives an idea of DTC implementation, different techniques to improve system performance etc.

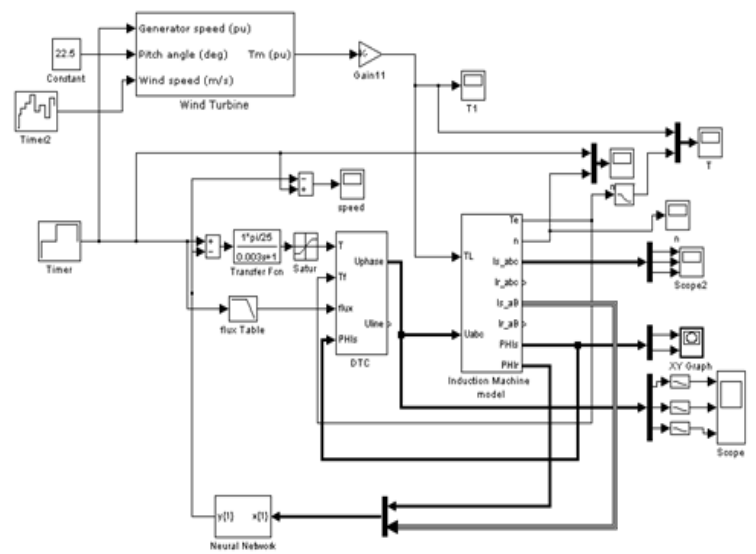

Fig. 5.1. Shows the construction of the desired system using MATLAB/ SIMULINK

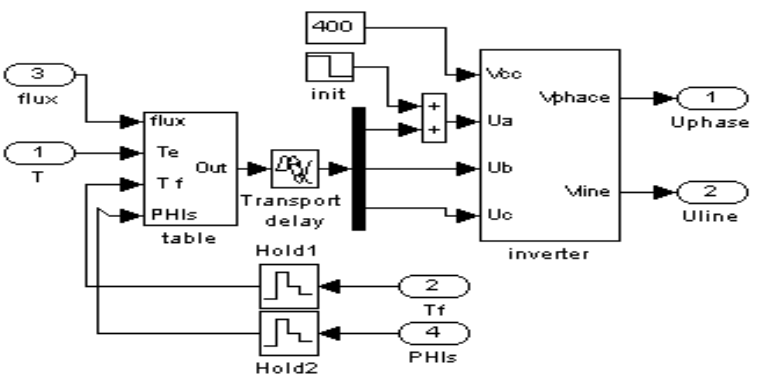

Fig. 5.2. Design of complete DTC mechanism
We will be getting the desired flux linkage from the speed reference using flux table.

From the Fig 5.2, we can observe that from flux linkage and torque developed, we can derive voltage vectors.

The DTC subsystem includes, table to convert estimated flux, stator flux, and electromagnetic torque, reference torque to get the three phase voltages $\mathrm{Ua}, \mathrm{Ub}$ and Uc Fig 5.1.

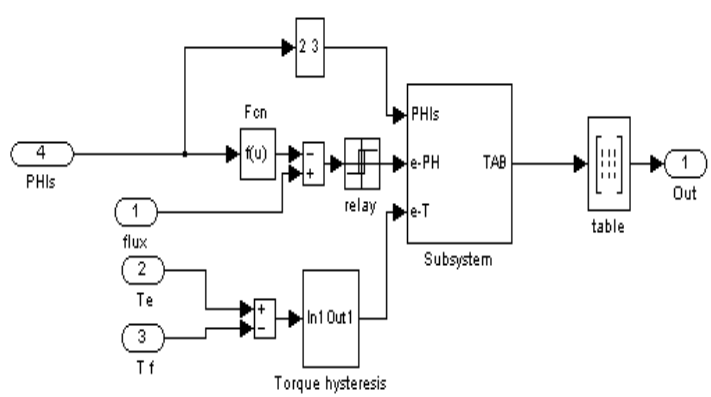

Fig. 5.3. Showing subsystem to achieve output voltage

The subsystem to derive output voltage is as shown in fig 5.3. The construction of estimated parameters to get torque estimated. The PHIs is stator flux $\left(\mathrm{I}_{\mathrm{sd}}, \mathrm{I}_{\mathrm{sq}}\right)$ is converted from 2 to 3 dimensional by using inverse parks transformation to get the voltage parameter for logic table as shown in fig 5.2. The PHIs is stator flux (magnitude of $\mathrm{I}_{\mathrm{sd}}$, $I_{\mathrm{sq}}$ ), of the machine output is compared with the reference flux estimated using flux table with a relay to get the phase voltages. When comparing estimated torque and actual torque using torque hysteresis shown in fig 5.4, we get the terminal voltage e-T.

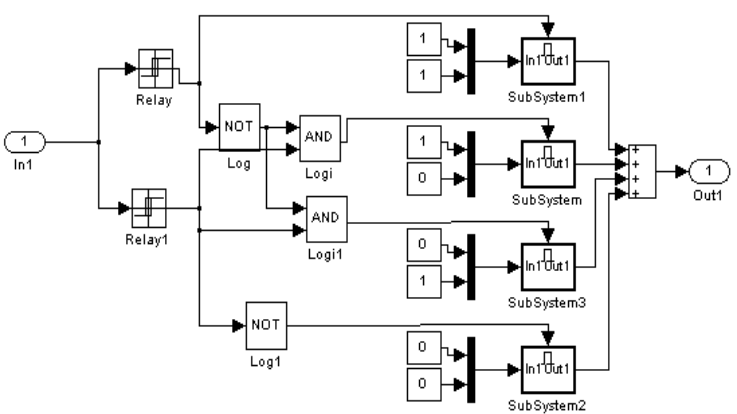

Fig. 5.4. Showing torque hysteresis control.

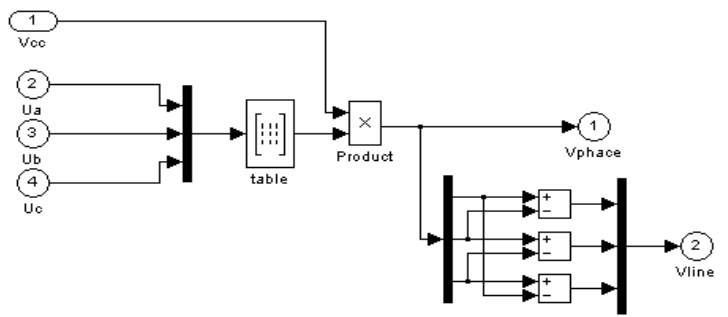

Fig. 5.5. Showing subsystem for the design of inverter circuit for the wind turbine IG set.

From Fig 5.3 to 5.5, from stator flux (PHIs), we get stator voltage, e-PH and e-T, and the logic table and transport delay, we will be getting phase voltages Uab, Ubc and Uca and phase to neutral voltages as shown in fig 5.1 and these variables will be input for the inverter system as shown in fig 6.5. Using this circuit we get the input voltage (both phase voltage and line voltage) to the wind turbine and 
induction generator set. The combinational logic for this

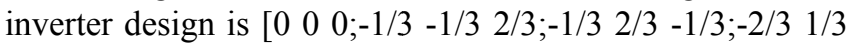
$1 / 3 ; 2 / 3-1 / 3-1 / 3 ; 1 / 3-2 / 31 / 3 ; 1 / 31 / 3-2 / 3 ; 0000]$;

\section{B. Induction Generator Implementation in Mat Lab/ Semolina}

The phase voltage output from the inverter circuit is fed to the IG set, and the implementation is shown in fig 5.7. The torque input to this machine, we get from the wind turbine system.

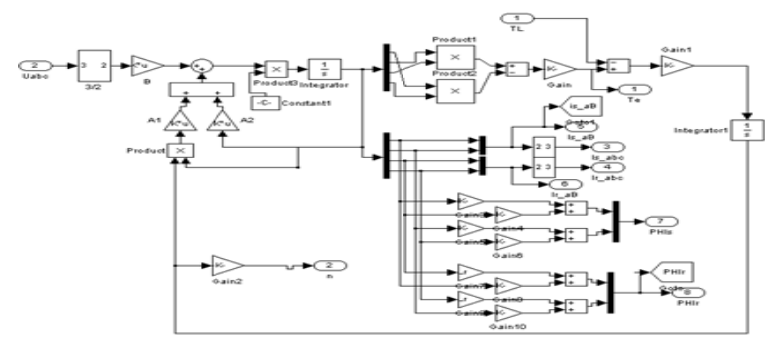

Fig. 5.7. Shows, the implementation of induction machine model.

Electrical sub-model of the induction motor the threephase to two-axis voltage transformation is achieved using the following equation. Where Vas, Vbs, and Vcs are the three-phase stator voltages, while Vds and Vqs are the twoaxis components of the stator voltage vector torque submodel of induction motor In the two-axis stator reference frame, the electromagnetic $\mathrm{T}$ is given by $[2,3,4,5]$

$$
\begin{gathered}
{\left[\begin{array}{l}
V_{d s} \\
V_{q s}
\end{array}\right]=\left[\begin{array}{ccc}
1 & -1 / 2 & -1 / 2 \\
0 & \sqrt{3} / 2 & -\sqrt{3} / 2
\end{array}\right]\left[\begin{array}{l}
V_{a s} \\
V_{b s} \\
V_{c s}
\end{array}\right]_{(16)}} \\
T=\frac{P L_{m}}{3}\left(i_{d r} i_{q s}-i_{q r} i_{d s}\right)
\end{gathered}
$$

Mechanical sub-model of induction motor from the torque balance equations and neglecting viscous friction, the rotor speed wo may be obtained as follows

$$
\omega_{0}=\int_{\tau=0}^{\tau} \frac{T-T_{L}}{J} \mathbf{d} \tau
$$

where $\mathrm{J}$ is the moment of inertia of the rotor and load and TL is the load torque Stator current output sub-model. The stator current output sub-model is used to calculate the stator current amplitude according to the following equation

$$
\left|i_{s}\right|=\frac{2}{3} \sqrt{\left(i_{d s}^{e}\right)^{2}+\left(i_{q s}^{e}\right)^{2}}
$$

The machine parameters are as follows: $\mathrm{Rs}=2.7 \mathrm{ohm}$, $\mathrm{Rr}=2.23 \mathrm{ohm}, \mathrm{Ls}=0.3562 \mathrm{H}, \mathrm{Lm}=0.3425 \mathrm{H}, \mathrm{Lr}=0.3562 \mathrm{H}$, $\mathrm{P}=0.00825 \mathrm{kgm}^{2}, \mathrm{P}=2$, rated speed $=1500 \mathrm{rpm}, \mathrm{Ts}=0.0546$ $\mathrm{nm}, \mathrm{Tr}=0.160 \mathrm{~nm}$.

\section{Simulation Results}

Three cases were studied, first with constant generator speed and in second case, variable generator speed were compared with PI and ANN controller techniques. In both the cases, the wind speed changes as is described in section
6.4. In third case, the generator is made to run at very low speeds, zero and negative speeds keeping wind speed constant. Rated generator speed is $1500 \mathrm{rpm}$.

Case1: wind speed changes with place, time, season etc., for wind generation system, the wind rotates the blades, further it will rotate the wind shaft using some gear mechanism. The rotating shaft will be coupled to the induction generator or permanent magnet machine. We have considered induction generator in this study. Based on wind speed input to the wind turbine, electromagnetic torque will be the output. This torque is taken as reference in general for wind system

In this case, we are considering constant generator speed, and examining with changes in the wind speed, how the induction generator torque output changes.

For this we are considering the wind speed changes with time as shown in the fig 6.1. We have taken a timer block from MATLAB library to vary wind speed with time.

The results with ANN are compared with PI controller. In the figure 6.1, ANN is replaced in sub Fig 5.8a with PI Fig $5.8 \mathrm{~b}$

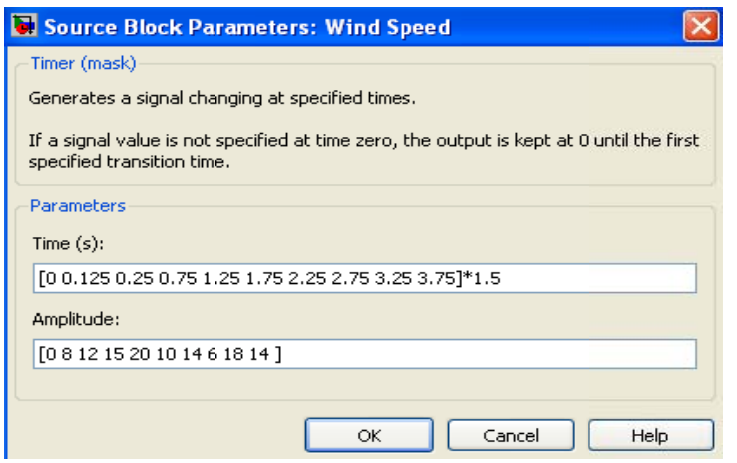

Fig. 6.1. Changes in wind speed $(\mathrm{m} / \mathrm{s})$ with time.

Examining the results, with changes in wind speed as in fig 6.1, the graph for stator flux $d$ and $q$ axis were shown in fig 6.2. Although with the changes because of wind speed, torque input changes to the generator, the trajectory between flux $\mathrm{d}$ and $\mathrm{q}$ does not change its circular motion. Hence the system is stable with transient response. For the speed of generator between 500 to $1500 \mathrm{rpm}$, PI will also work effectively like ANN, but with more torque ripples.

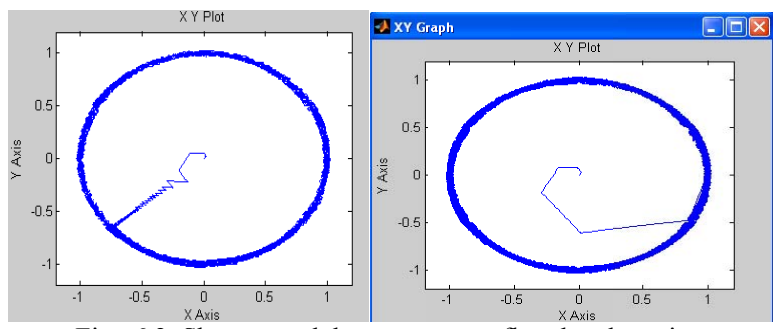

Fig . 6.2. Shows graph between stator flux $d$ and $q$ axis.

Now considering the time of response and its deviation from reference value, Fig 6.3 and 6.4 will be slef explainable. Fig 6.3 depicts, with reference torque change, the electromagnetic torque of the machine changes respectively. The deviation from reference to actual is as shown in Fig 6.4. The deviation is about 0.22 seconds and error value is about \pm 0.03 for ANN, but is very high with PI. 


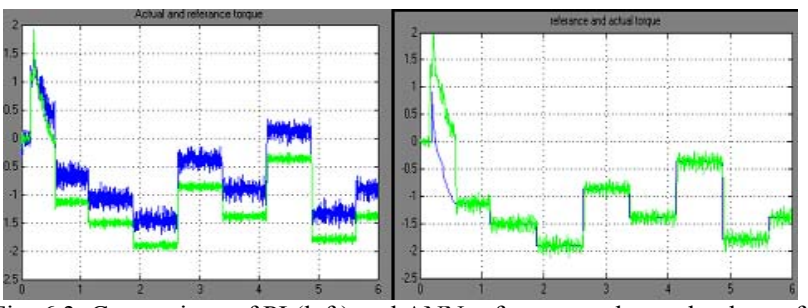

Fig. 6.3. Comparison of PI (left) and ANN reference and actual values of Electromagnetic torque

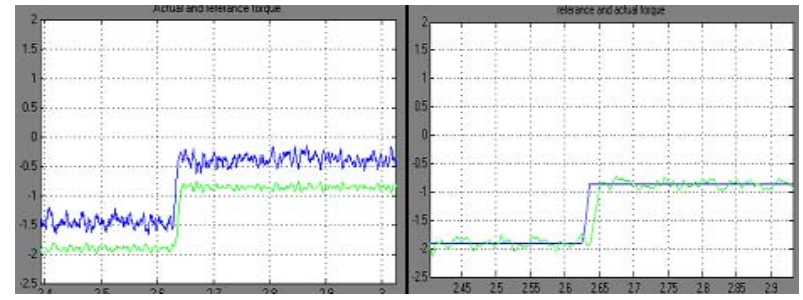

Fig. 6.4. Zoomed picture of actual and reference electromagnetic torque.

With changes in torque input of the machine, the speed is maintained constant, which is considered as 500rpm in this case. The deviation from $500 \mathrm{rpm}$ is about $+7.5 \mathrm{rpm}$ which can be negligible. Fig 6.5 shows the induction generator speed output with PI and ANN. Fig 6.6 is helpful in examining the torque output with change in wind speed is self explainable.
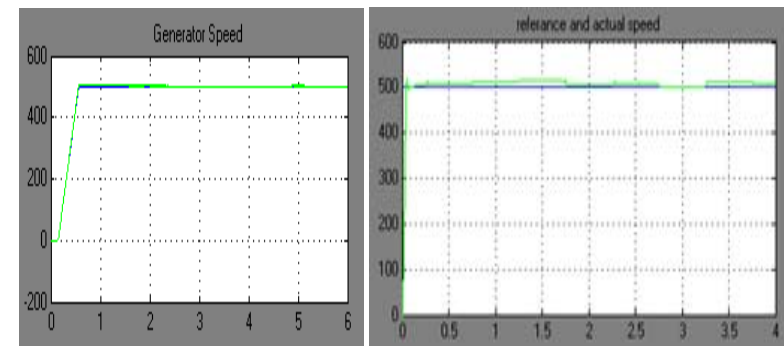

Fig. 6.5. Shows generator speed change with changes in electromagnetic torque, comparing PI(left) and ANN
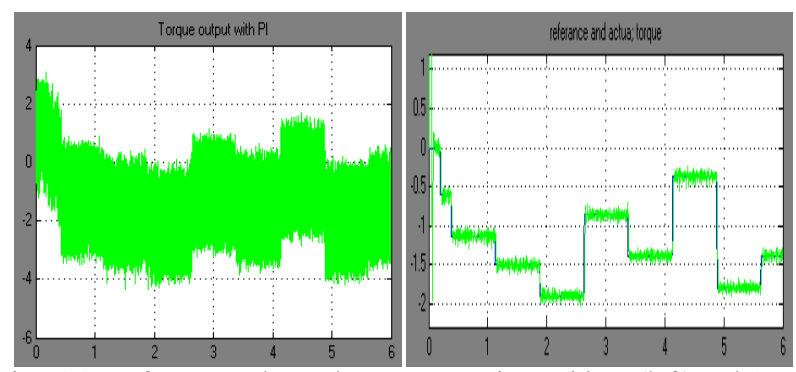

Fig. 6.6. Reference and actual torue comparison with PI (left) and ANN controllers

The torque output is having very low ripples with ANN compared to PI controller. Hence better control can be achieved with ANN proposed scheme.

The three phase (a, b and c) currents are shown in the figure 6.7 .
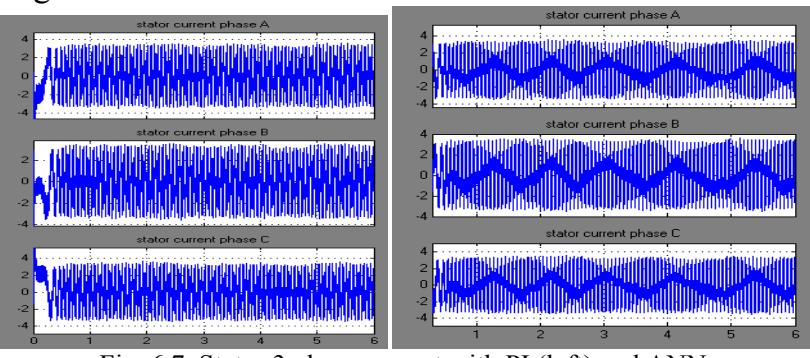

Fig. 6.7. Stator 3 phase current with PI (left) and ANN
The stator current is constant as, even with the changes the torque, the speed of the machine is maintained constant, so current is nearly constant, the zoomed picture of the Fig 6.7 is shown in Fig 6.8

Fig 6.11, 13 shows the trajectory of the estimated stator flux components DTC-SVM has as good dynamic response as the classical DTC.

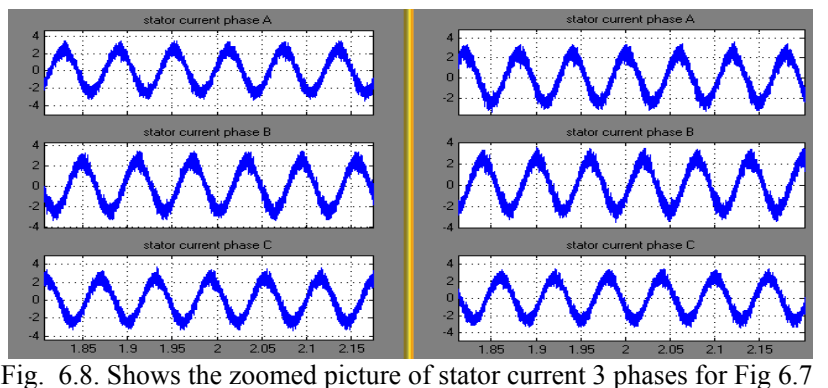

The stator voltages for the 3phases are shown in Fig. 6.9, the voltages are also constant and doesn't changed with torque change. The zoomed view of stator voltage is shown in Fig 6.10.
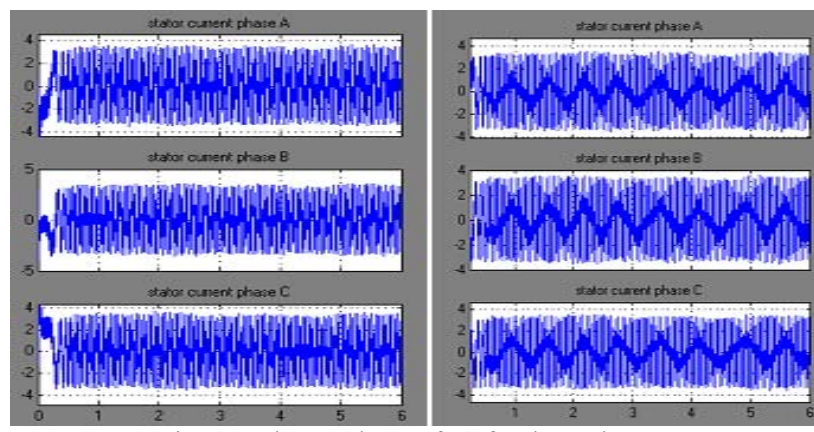

Fig. 6.9. Phase voltage of IG for three phases

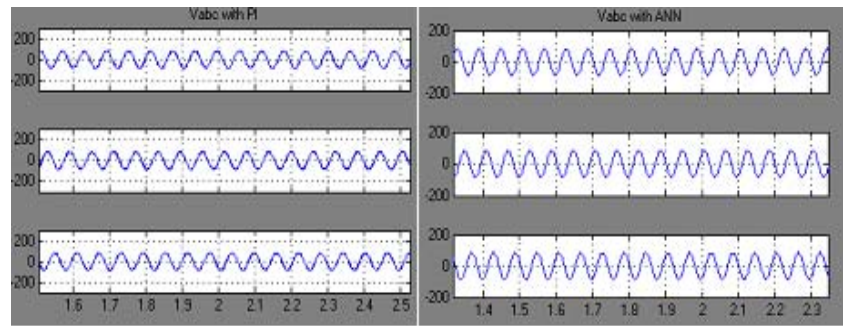

Fig. 6.10. Shows the zoomed vie of three phase stator voltage

Compared to PI, ANN proposed scheme is having lesser torque ripples, but current ripples are nearly same for both the techniques when generator runs at half of the rated speed.

Hence PI technique holds good for the constant generator speed between half rated to its full rated value with more variations in wind speed.

Case2: In this case, we are considering variable generator speed (comparing the constant speed in previous case), and examining with changes in the wind speed Fig 6.1, how the induction generator torque output varies.

The graph between stator flux $\mathrm{d}$ and $\mathrm{q}$ axis will be a circular trajectory. Any disturbance beyond stable operation, the path deviates from circular motion. Such state occurs when any internal fault occurs in the generator, or very high pitch angle of wind turbine at very low generator speed, much change in the slip of IG etc. 


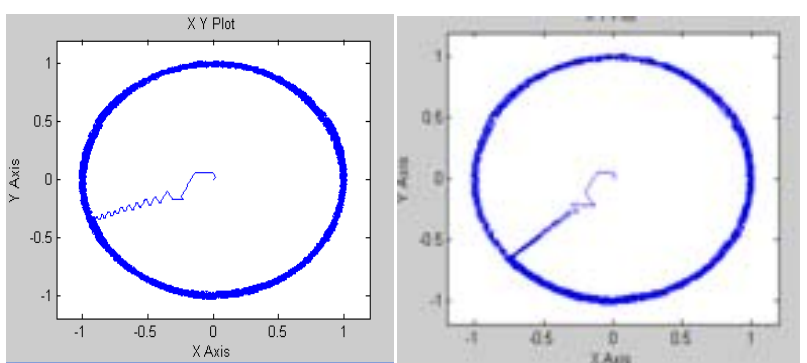

Fig. 6.11. Shows graph between stator flux $\mathrm{d}$ and $\mathrm{q}$ axis.

Also with the change in generator speed and torque, the circular trajectory as in Fig 6.11 does not change. This trajectory graph is between stator flux $\mathrm{d}$ and $\mathrm{q}$ axis in pu. This shows that with transients in the form of speed variation or on load, the system will be in bounded state. The speed of induction generator change with respect to as 500, 1000 and 1500rpm at 0.015, 1.5 and 3.75 seconds respectively in this work.
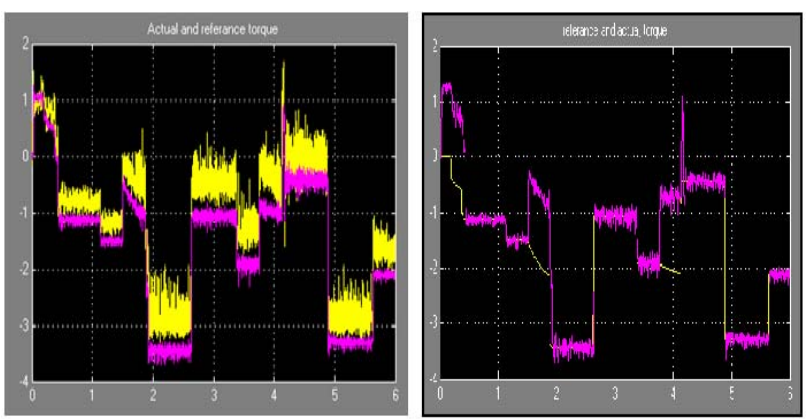

Fig. 6.12. Shows reference and actual value of electromagnetic torque using PI (left) and ANN (right).

As with change in wind speed, the electromagnetic torque varies. With reference to the fig 6.12, wind speed variation brings deviation in torque value with reference value. The comparison of the system with PI and ANN, the deviation from reference to actual is very small in later. Also in ANN, the deviation at $0.001 \mathrm{~s}, 1.5 \mathrm{~s}$ and $3.5 \mathrm{~s}$ can be observed. It is due to sudden speed variation, but it can follow with very little delay.

From Fig 6.12, we can conclude that the generator torque is little low compared to reference torque with PI controller. In ANN system, actual torque follows reference torque. The deviation from reference to actual torque can be observed in the time when speed is changing, when it has reached specified speed, instantly torque follows, this ANN technique is better applicable when many generator speed variations are required and to operate very stably.

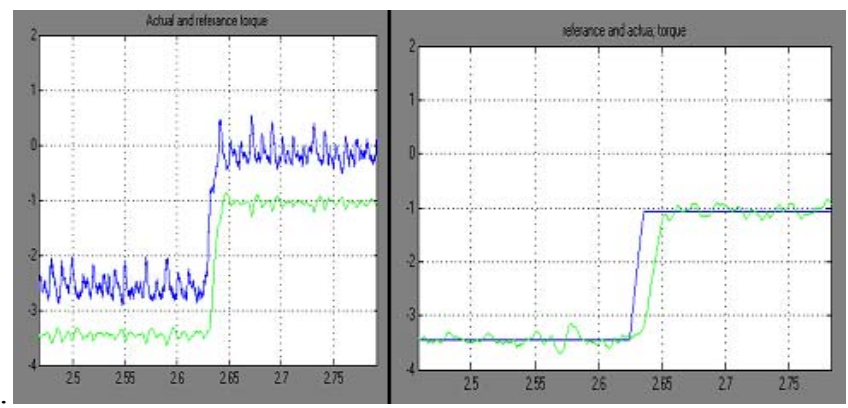

Fig. 6.13. Shows the zoomed relation of reference (blue) and actual (green) torque parameters with PI (left) and ANN

The deviation of actual and reference values are zoomed as shown in Fig 6.13 the deviation is nearly 0.05 seconds. In PI controller, the deviation to reference is higher compared to PI controller. With earlier techniques proposed by many authors, the torque following will have many ripples. [5,6, 9-34]. The proposed system is having very low torque ripples and speed of operation also improved and the neural network is having supervisory learning mechanism.

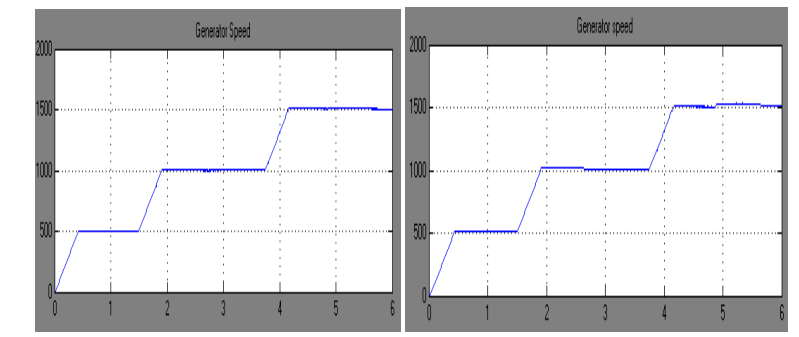

Fig. 6.14. Shows the variation of generator speed reference to actual with PI (left) and ANN (right)

The generator reference speed can be observed from Fig. 6.14 using PI and ANN controller. With changes in the generator speed reference, the actual machine speed follows without any delay and deviation. Hence DTC implementation using PI and ANN system is very accurate.
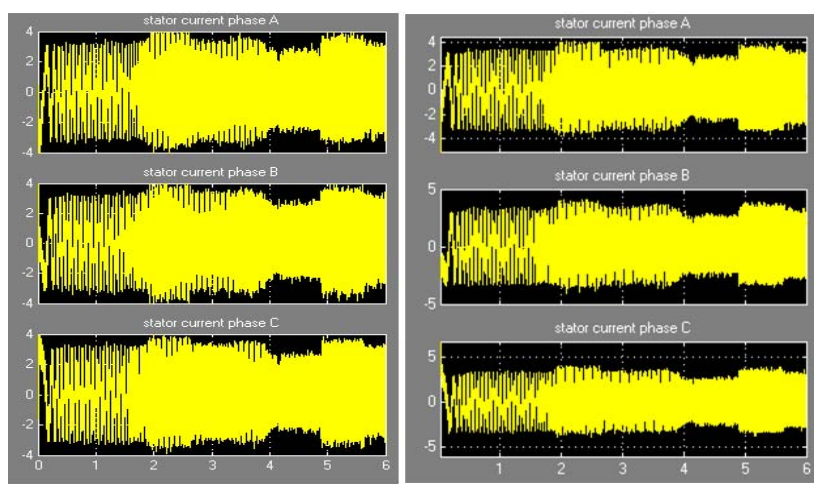

ig. 6.15. Shows the stator three phase current with PI (left) and ANN technique

With the changes in the wind generator speed, the stator current and voltage frequency is varied. When the induction generator reference speed varies at time $0.15,1.5$ and 3.75 seconds, the frequency of generator stator current and phase voltage changes as shown in Fig 6.15 and 6.16. In both PI and ANN techniques, the current and voltage harmonics are low, even low in ANN scheme. But there is a requirement of cyclo-converter to acquire the rated voltage and frequency.
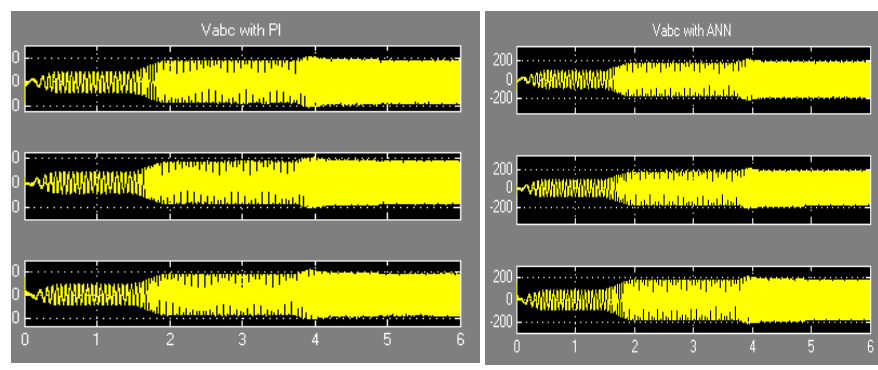

Fig. 6.16. Shows the variation of stator phase voltages with time, comparing with PI (left) and ANN

As speed increases, the generator back emf increases and vice versa. Also with the back emf, the terminal voltage and frequency also increases. We can observe the changes in 
magnitude of voltage and frequency with changes in Fig. 6.19. Shows the current and voltage waveforms for different using ANN generator speed variation.

With the electric power demand, we can supply the load centers with nearly constant voltage and frequency, but change in current. This proposed system will follow the reference path in less than 0.02 seconds (fig 6.4, 6.14). Even the flux linkages were also maintained constant (fig 6.11), even with transient changes in load torque and also with machine speed. This technique holds good for normal IG drive system with positive and negative torque coefficients.

To deviation in speed, PI controller is taking time,. The torque surges with PI are very high with variation in generator speed. The speed error is in range +27 and $-31 \mathrm{~m} / \mathrm{s}$ for PI, for ANN it is +15 to $-22.5 \mathrm{~m} / \mathrm{s}$.

Case 3: the system is tested using low speed, zero and reverse speed operation at wind speed of $1 \mathrm{~m} / \mathrm{s}$ and $10 \mathrm{~m} / \mathrm{s}$.

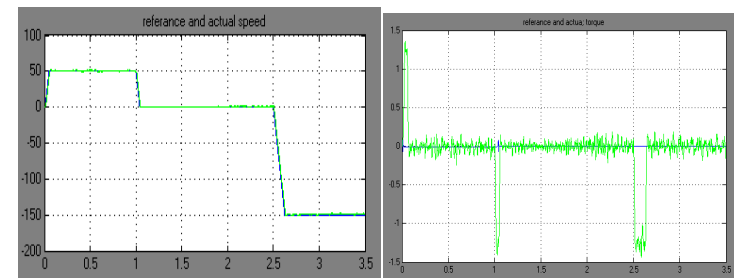

Fig. 6.17. Shows the variation of speed and torque with time using PI controller with $\mathrm{Cp}=10^{\circ}$ and wind speed $1 \mathrm{~m} / \mathrm{s}$

In fig 6.17 , at very low wind speed $(1 \mathrm{~m} / \mathrm{sec})$, the generator torque output is also very low. When the generator speed is very low and changing as [50 0 - 150$]$ $\mathrm{rpm}$, the toque value with PI controller is nearly $0 \mathrm{~N}-\mathrm{m}$, but the change in speed, brings transients in the generator. Here the change in speed brings transient in torque to nearly $1.5 \mathrm{~N}-\mathrm{m}$.

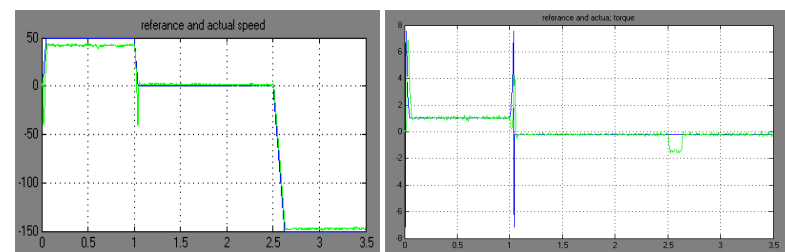

Fig. 6.18. Shows the variation of speed and torque with time using ANN controller with $\mathrm{Cp}=22.5^{\circ}$ and wind speed $10 \mathrm{~m} / \mathrm{S}$

In fig 6.18, with rated wind speed $(10 \mathrm{~m} / \mathrm{sec})$, the generator torque output is very low because the generator speed is very low [ $500-150] \mathrm{rpm}$ at $1.5 \mathrm{~N}-\mathrm{m}$ at $50 \mathrm{rpm}$, but the sudden change in speed at full load torque brings transients in the generator with $\pm 7 \mathrm{Nm}$ and after disturbance the system is stable instantly with $0 \mathrm{Nm}$. When the generator made to run (50 to $-500 \mathrm{rpm}$ ) speeds, with $1 \mathrm{~m} / \mathrm{s}$ wind speed does not comprise any transients unlike fig. 6.17

The high pitch angle of wind turbine affects the system at low generator and wind speeds. But the influence was alleviated by using this ANN technique.

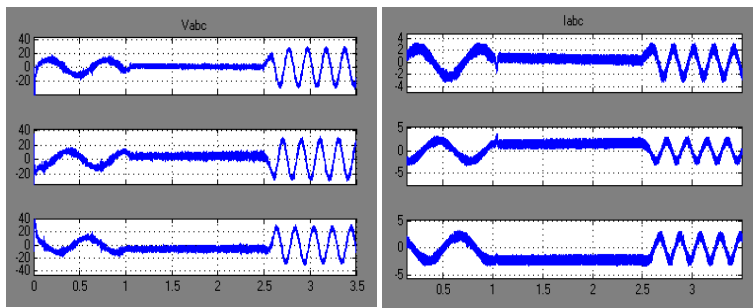

Fig. 6.21. Shows the Speed and torque waveforms using ANN controller with $\mathrm{Cp}=10^{\circ}$ and wind speed $10 \mathrm{~m} / \mathrm{s}$

The speed and torque waveforms of the generator with ANN controller is in fig 6.21, the generator torque output is very low even at rated wind speed $(10 \mathrm{~m} / \mathrm{sec})$, due to low generator speed. The toque value with ANN controller is nearly $-0.2 \mathrm{Nm}$ at $50 \mathrm{rpm}$, but the change in speed from 50 to 0 brings $\pm 7 \mathrm{Nm}$ transients explained as in fig 6.18. The system is stable at full wind speed and zero generator speed. With full load and reverse speed operation on generator set, the system is completely stable with ANN controller.

When the generator speed reference was changed, during time to reach 0 to $-1000 \mathrm{rpm}$, we can observe little deviation in the torque due to slip of the machine.

\section{CONCLUSIONS}

From the analysis and simulations, a command flux optimization scheme has been proposed to reduce the speed and torque ripples. From the results it is obvious that there is :

- Reduction of torque and current ripples in transient and steady state response,

- No flux droops when speed of the machine changes as there is no deviation in circular trajectory of stator flux $d$ 
and q axis.

- Fast stator flux response, so speed and torque can reach its predicted state without much delay.

It permits to estimate the rotor flux independently from the estimated speed, like in Shauder (1992) and Ben-Brahim and Kurosawa (1993), and differently from any full-order observer, which makes the observer more robust.

Simulation results demonstrate the feasibility and validity of the proposed ANN-DTC system for wind turbine IG set. Standing in vivid contrast against traditional DTC system, after ANN control and DTC technology is used, this intelligent system effectively accelerates, speed and torque response, reduces torque and flux ripple, achieves fixed switch frequency and improves system performance. The proposed intelligent DTC simulation model provides an effective method for studying DTC. In comparison with the traditional DTC-PWM, the new scheme eliminates the impact of the coupled items, and achieves high robustness against disturbance.

Comparing with development in DTC technology from 2008 to $10,[26-28,35-40]$, torque ripples in this scheme were reduced with ANN.

With reference to $[35,41 \& 42]$, even at low speeds or sudden speed reversal, the proposed scheme is very advantageous.

Comparing with [36], the speed response to reach its refereed state is very low in proposed scheme.

In [37], comparing to fig 6.10 in that paper, the stator current in proposed scheme is very sinusoidal.

For example in $[37,38]$, comparing with the speed and torque deviations from reference values, the proposed scheme is having better attenuation (fig 6.12, 6.14, 6.17, 6.21)..

It resolves the open-loop integration problem using a new adaptive neural system, works at any frequency.

Therefore, the disturbance rejection is independent of system model, and the efforts to compensate disturbance is integrated in the output of ANNSP, which simplifies the structure of the system.

By using it as a adaptive predictor and not as simulator, it improves the speed convergence of the training algorithm.

Simulation results demonstrate the satisfactory performance and effectiveness of proposed approach (fig $6.13,6.14,6.18)$.

Choosing cut off frequency close to ready frequency reduces DC shift in the stator voltage (Fig. 6.16, 6.19). Nevertheless, this leads to phase and amplitude errors, former in voltage leads to loss of control, later, on the other hand, causes voltage and torque to have higher values (Fig 6.12 ), than the reference values and field weakening cannot be obtained due to voltage saturation.

At low, zero speed or negative speed; even at low load on the system, the torque ripples are very high with PI, whereas with high load on generator, high pitch angle, the proposed ANN scheme holds great responsibility to maintain stable and follows its refereed path (Fig 6.17 to 6.21).

\section{RELATED WORKS}

Lot of research work is being done to control the alternating current machines. Some control mechanisms like sensorless DTC, Extended Kalman Filter, SVPWM, and Artificial Intelligence based techniques with some recent trend, has led to a promising control of machine parameters, also improves efficiency of overall system. The work in this paper has got inspiration from "Design of self-tuning pitype fuzzy controller [22], robust control of Induction Motor Drive (IMD) using SVM technique [23, 24]", So studying these papers, and present problems in wind-turbine system, speed and power control, the proposed technique in this paper might be helpful.

\section{APPENDIX}

The machine parameters are as follows: $\mathrm{Rs}=2.7 \mathrm{ohm}$, $\mathrm{Rr}=2.23 \mathrm{ohm}, \mathrm{Ls}=0.3562 \mathrm{H}, \mathrm{Lm}=0.3425 \mathrm{H}, \mathrm{Lr}=0.3562 \mathrm{H}$, $\mathrm{P}=0.00825 \mathrm{kgm}^{2}, \mathrm{P}=2$, rated speed $=1500 \mathrm{rpm}, \mathrm{Ts}=0.0546$ $\mathrm{nm}, \mathrm{Tr}=0.160 \mathrm{~nm}$.

\section{REFERENCES}

[1] P. C. Krause, "Simulation of symmetrical induction machinery," IEEE T rans. Power Apparatus Systems, Vol. PAS-84, No. 11, pp. $1038-1053$ (1965)

[2] S. N. Ghani, "Digital computer simulation of three-phase induction machine dynamics - a generalized approach," IEEE Trans Industry Appl, Vol. 24, No. 1, pp. 106-114 (1988)

[3] S. Wade, M. W. Dunnigan, and B. W. Williams, "Modeling and simulation of induction machine vector control and rotor resistance identification," IEEE T rans. Power Electronics, Vol. 12, No. 3, pp. 495-505 (1997)172

[4] K. L. Shi, T. F. Chan, and Y. K. Wong, "Modelling of the threephase induction motor using SIMULINK," Record of the 1997 IEEE International Electric Machines and Drives Conference, USA, pp. WB3-6 (1997)

[5] K. L. Shi, T. F. Chan, and Y. K. Wong, "Modelling and simulation of direct self control system," IAST ED International Conference: Modelling and Simulation, Pittsburgh, USA, pp. 231-235 (May 1998)

[6] G. Foo, S. Sayeef, and M. F. Rahman, "Wide Speed Sensorless SVM Direct Torque Controlled Interior Permanent Magnet Synchronous Motor Drive," 1439-1444, 2008 IEEE.

[7] Using SIMUL INK, Dynamic System Simulation for MATLAB, The Mathworks Inc. (1997)

[8] P. C. Krause, O. Wasynczuk, and V, S. D. Sudho, Analysis of Electric Machinery, IEEE (1995)

[9] Technical Guide No.1- Direct Torque Control http://www.abb.com/ motors, drives

[10] K-K. Shyu, L. J. Shang, H-Z. Chen, and K-W Jwo, Flux Compensated Direct Torque Control of Induction Motor Drives for Low Speed Operation. IEEE Transactions on Power Electronics, vol. 19, no. 6, November 2004

[11] K. L. Shi, T. F. Chan, Y. K. Wong, and S. L. Ho, Estimation of an Induction Motor Drive Using an Optimized Extended Kalman Filter. IEEE Transaction on Industrial Electronics, vol. 49, no. 1, February 2002.

[12] T. B. Reddy, B. K. Reddy, J. Amarnath, D. S. Rayudu, and Md. H. Khan, Sensorless Direct Torque Control of Induction Motor based on Hybrid Space Vector Pulsewidth Modulation to Reduce Ripples and Switching Losses - A Variable Structure Controller Approach. IEEE Power India Conference, 10-12 April 2006.

[13] G. S. Buja and M. P. Kazmierkowski, Direct Torque Control of PWM Inverter-Fed AC Motors - A survey. IEEE Transactions on Industrial Applications, vol. 51, pp. 744-757, August 2004.

[14] M. Depenrock, "Direct self-control of inverter-fed machine," IEEE Trans. Power Electron., vol. 3, pp. 420-429, Oct. 1988.

[15] I. K. Buehring and L.L. Freris, "Control policies for wind energy conversion systems,” Proc. Inst. Elect. Eng. C, vol. 128, pp. 253-261, Sept. 1981.

[16] M. R. Patel, Wind and Solar Power Systems, CRC Press, 1999.

[17] S. N. Bhadra, D. Kastha, S. Banerjee, Wind Electrical Systems, OXFORD University Press, 2005.

[18] J. J. Brey, Castro, A, E. Moreno, and C. Garcia, "Integration of renewable energy sources as an optimised solution for distributed generation," IECON 02 [Industrial Electronics Society, IEEE 2002 
28th Annual Conference of the, Vol. 4, 5-8 Nov., pp.:3355 - 3359, 2002.

[19] S. H. Chichester, Grid integration of wind energy conversion systems, Wiley, 385p, 1999.

[20] R. T. S.Meziane and H. Benalla, "Direct torque control for induction motor using intelligent techniques," Journal of Theoretical and Applied Information Technology, pp 35-44, 2007.

[21] K. T. S. Islam: "Optimum control strategies in energy conversion of pmsg wind turbine system without mechanical sensors," IEEE Transactions on Energy Conversion, vol. 19, no. 2, June 2004, pp.392-399

[22] J. L. P. Azcue and E. Ruppert, "Three-phase Induction Motor DTCSVM Scheme with Self-Tuning PI-Type Fuzzy Controller" IEEE 2010 Seventh International Conference on Fuzzy Systems and Knowledge Discovery (FSKD 2010), June 2010, pp. 757-762.

[23] S. D. Liu, Y. Sun, F. Zhang, and H. Yan, "Study on DTC-SVM of PMSM Based on Propeller Load Characteristic" IEEE World Congress on Intelligent Control and Automation, June 25 - 27, 2008, pp. 6445-6449.

[24] F. M. A. kader, A. E. Saadawi, A. E. KALAS, O. M.E. baksawi, "Study In Direct Torque Control of Induction Motor By Using Space Vector Modulation," Aug 2008, pp-224-229.

[25] C. Cao, F. Li, K. Zhang, H. Zhang, H. San, "Chaos Optimizing BPNNG Speed Recognition in DTC System," IEEE International Symposium on Intelligent Information Technology Application Workshops, Aug2008, pp. 1077-1080.

[26] B. C. Babu and C. Poongothai, "High Performance Direct Torque Controlled Induction Motor Drive For Adjustable Speed Drive Applications," 2008 IEEE First International Conference on Emerging Trends in Engineering and Technology pp. 927-932.

[27] R. Kumar and S. V. Padmanaban, "An Artificial Neural Network Based Rotor Position Estimation for Sensorless Permanent Magnet Brushless DC Motor Drive,” IEEE conf. (IECON-2006), Nov. 2006, pp.649-654.

[28] B. Kosko, "Neural Networks and Fuzzy Systems: A Dynamic Systems Approach to Machine Intelligence", Englewood Cliffs, NY Prentice Hall 1992.

[29] B. K.Bose. "Neural Network Applications in Power Electronics and Motor Drives-An Introduction and Perspective", IEEE Trans. Ind. Elec., Vol 54, No. 1. 2007, pp. 14-32.

[30] G. Cirrincione, M. Cirrincione, Chuan Lu, and M. Pucci, "Direct torque control of induction motors by use of the GMR neural network" Int. Joint Conf. on Neural Networks Vol. 3, 20-24 July 2003, pp. $2106-2111$.

[31] P. P. Cruz and J. J. R. Rivas, "A small neural network structure application in speed estimation of an induction motor using direct torque control" IEEE Power Electronics Specialists Conf.(PESC. 2001) Vol. 2, June 2001, pp. $823-827$.

[32] M. Vasudevan and R. Arumugam "High - Performance Adaptive Intelligent Direct Torque Control Schemes For Induction Motor Drives," KMITL Sci. Tech. J. Vol. 5, July-Dec. 2005, pp. 559-576.

[33] C. Martins, X. Roboam, T. A. Meynard, and A. S. Caryalho, "Switching Frequency Imposition and Ripple Reduction in DTC
Drives by Using a Multilevel Converter," IEEE Trans. Power Electron., vol. 17, issue 2, pp. 286-297, March 2002.

[34] L. Tang, L. Zhong, M. F. Rahman, and Y. Hu, "A Novel Direct Torque Control for Interior Permanent Magnet Synchronous Machine Drive System with Low Ripple in Flux and Torque and Fixed Switching Frequency," IEEE Trans. Power Electron., vol. 19, pp. 346-354, March 2004

[35] G. Adamidis and M. Leibadaras, "evaluation of methods of speed estimation of asynchronous motor based on direct torque control (dtc)," 2010 IEEE, SPEEDAM 2010, International Symposium on Power Electronics, Electrical Drives, Automation and Motion, pp 1008-1011.

[36] M. N. Uddin, and M. Hafeez, "FLC Based DTC Scheme to Improve the Dynamic Performance of an IM Drive," 2010 IEEE

[37] J. Beerten, J. Verveckken, and J. Driesen, "Prediction-based ripple reduction in Direct Torque Control of an induction machine," Proceedings of the 2008 International Conference on Electrical Machines, 2008 IEEE, pp 1-6

[38] J. Liu and W. 1. Wang, WANG Yang, "Research on FOC and DTC Switching Control of Asynchronous Motor based on Parameter Estimation," Proceedings of the IEEE International Conference on Automation and Logistics Qingdao, China September 2008, pp. 17541758.

[39] X. J. Yao, X. D. Wang and S. Liu, "Research of variable-speed and constant frequency double fed generator based on DTC," 2010 International Conference on Optics, Photonics and Energy Engineering,pp 30- 33

[40] C. Z. Cao, W. J. Wang, F. k. li, "Rotor speed identification on dtc system based on neural network of new chaos optimizer algorithms," Proceedings of the Seventh International Conference on Machine Learning and Cybernetics, Kunming, 12-15 July 2008, pp 824-828.

[41] T. Satish, K. K. Mohapatra, and N. Mohan, "Dynamic Performance of a Matrix Converter Fed Speed Sensorless DTC Induction Motor Drive Using Adaptive Speed Observer," Applied Power Electronics Conference and Exposition, 2009. APEC 2009. Twenty-Fourth Annual IEEE, pp. $1984-1990$.

[42] M. Cirrincione and M. Pucci, "Sensorless direct torque control of an induction motor by a TLS-based MRAS observer with adaptive integration," Science direct, 25 August 2005, Volume 41, Issue 11, November 2005, IFAC meeting, Pages 1843-1854.

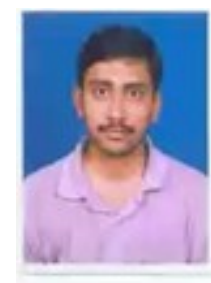

D.V.N. Ananth was born in Visakhapatnam, India on $20^{\text {th }}$ August 1984. He received B.Tech Electrical Engineering from Raghu Engineering College, Visakhapatnam and M.Tech from Sreenidhi Institute of Science \& Technology, Hyderabad, India. He is working as an Assistant Professor in VITAM College of Engineering in Electrical Department. His favorite topics include Renewable electrical systems, industrial drives, power systems, power electronics, control systems, HVDC and Reactive power compensation techniques. 